Disponível em:

http://editora.unoesc.edu.br/index.php/race

Race, Joaçaba, v. 15, n. 2, p. 751-778, maio/ago. 2016

\title{
O IMPACTO DOS SERVIÇOS AO CLIENTE NO MARKETING DE RELACIONAMENTO ENTRE MINIMERCADOS E SEUS FORNECEDORES
}

The impact of customer service in marketing relationship between minimarkets and its suppliers

Aline Mara Meurer

E-mail: alinemeurer@upf.br

Mestre em Administração de Empresas pela Pontifícia Universidade Católica do Rio Grande do Sul; doutoranda em Administração pela Universidade Católica do Rio Grande do Sul; Professora do curso de Administração na Universidade de Passo

Fundo; Endereço para contato: Rodovida BR 285, São José, 99052-900, Passo Fundo, Rio Grande do Sul, Brasil.

Verner Luis Antoni

E-mail: antoni@upf.br

Doutor em Engenharia da Produção pela Universidade Federal de Santa Catarina;-

Mestre em Administração pela Universidade Federal do Rio Grande do Sul; Pesquisador e Professor do Programa de Pós-Graduação em Administração da Faculdade de Ciências Administrativas, Econômicas e Contábeis da Universidade de Passo Fundo.

\section{Cassiana Maris Lima Cruz}

E-mail: cassiana@upf.br

Doutora em Comunicação Social pela Pontifícia Universidade Católica do Rio Grande do Sul; Mestre em Administração pela Universidade Federal de Santa Catarina; Pesquisadora e Professora do Programa de Pós-Graduação em Administração da Faculdade de Ciências Administrativas, Econômicas e Contábeis da Universidade de Passo Fundo.

Artigo recebido em 13 de maio de 2015. Aceito em 29 de fevereiro 2016. 
Resumo

Em um ambiente de acirrada competição, a construção de relacionamentos sustentáveis entre os participantes de um canal comercial assume maior importância, tornando o desenvolvimento de parcerias estratégicas e cooperação mútua fundamental para as empresas aumentarem sua competitividade no mercado. Considerando esse contexto, com o estudo desenvolvido objetivou-se examinar as relações existentes entre os serviços ao cliente e o marketing de relacionamento nas transações entre minimercados e seus principais fornecedores. A mensuração do marketing de relacionamento foi feita por meio da escala proposta por Wilson e Vlosky (1997), e o nível de serviços ao cliente foi verificado pelos indicadores de serviços, gerados em uma etapa exploratória com gestores de minimercados. Utilizando-se Regressão Múltipla foi possível identificar que os serviços ao cliente apresentam influência no relacionamento do canal estudado. Os resultados também demonstram que o relacionamento entre minimercados e seus fornecedores é frágil, exceto na dimensão comprometimento.

Palavras-chave: Marketing de relacionamento. Serviços ao cliente. Canal de marketing. Minimercados.

\section{Abstract}

In a tough competitive environment, building sustainable relationships between the participants of a commercial channel assumes greater importance, making the development of strategic partnerships and mutual cooperation essential for the companies that wish to improve their competitiveness in the market. Given this context, the study developed aimed to examine the existing relationship between customer services and relationship marketing in transactions between minimarkets and its main suppliers. The relationship marketing measurement was evaluated through the scale proposed by Wilson and Vlosky (1997), and the level of customer service was verified through service indicators generated in an exploratory stage with minimarkets owners. Through Multiple Regression it was found that customer services influence in this study channel. The results showed that the relationship between mini-markets' owners and their suppliers is fragile, except on the commitment dimension.

Keywords: Relationship marketing. Customer services. Marketing channel. Minimarkets.

\section{INTRODUÇÃO}

Diversos estudos foram realizados no sentido de melhor compreender a estrutura conceitual do marketing de relacionamento (DWYER; SCHURR; OH, 1987; MORGAN; HUNT, 1994; WILSON; VLOSKY, 1997; SHETH; PARVATIYAR, 2000; CHANG et al., 2012; GEIGER et al., 2012; HADJIKHANI; LAPLACA, 2013; PA- 
TIL; PATIL, 2014) e a importância dos serviços ao cliente nas trocas estabelecidas nos canais de marketing (FRAZIER, 1999; BOWERSOX; DAUGHERTY, 1992; INNIS; LA LONDE, 1994; STERN et al., 2002; CHRISTOPHER, 2007; SLONGO; MÜSSNICH, 2005; COUGHLAN et al., 2011). Essa ênfase pode ser atribuída à necessidade de serem identificados mecanismos que proporcionem às empresas, independente de seu porte, atingirem níveis superiores na entrega de valor aos clientes, oportunizando vantagens competitivas perante seus concorrentes.

O marketing de relacionamento tem sido associado às tentativas de se desenvolverem relacionamentos de longo prazo, podendo vir a oferecer uma vantagem competitiva à medida que contribui à diferenciação do produto e cria barreiras à mudança (DAY; WENSLEY, 1983; DWYER; SHURR; OR, 1987). Nesse sentido, Slongo (1996), ao discutir o marketing de relacionamento, indica que as incertezas vivenciadas pelas empresas em razão de aspectos como avanço tecnológico, automação industrial, abertura de mercado e maior nível de exigência dos clientes tornam importante a busca por relacionamentos consistentes e duradouros entre parceiros de um canal de marketing.

Simultaneamente, os serviços ao cliente, na concepção de autores como La Londe e Zinszer (1976), Bowersox e Daugherty (1992) e Abbade e Noro (2012), também trazem oportunidades e benefícios para as empresas, pois além de constituírem uma estratégia capaz de ampliar a oferta básica dos produtos e, consequentemente, o potencial de diferenciação frente à concorrência, favorecem o desenvolvimento de uma relação positiva e duradoura com os clientes, a qual se traduz em repetição de compras, aumento da satisfação e lealdade. Quando o fornecedor aumenta a oferta de serviços ao cliente, evidencia o interesse em aumentar o investimento no relacionamento, buscando, assim, qualificar a dependência e a confiança do comprador no relacionamento comercial (SLONGO; MÜSSNICH, 2005).

Nesse contexto, considerando a importância da busca de diferenciação e do desenvolvimento de relações sólidas entre empresas e seus fornecedores, neste estudo teve-se como foco examinar o impacto dos serviços ao cliente no relacionamento estabelecido entre minimercados, intermediários em um canal de marketing, e seus fornecedores.

Em uma perspectiva teórica, são importantes estudos que avancem na compreensão das relações entre canais e na criação de valor entre estes, as quais, segundo Gummersson (2002) e Rocha e Luce (2006), são latentes e merecem ser exploradas, uma vez que propiciam às empresas possibilidades de construir e sustentar vantagens competitivas de longo prazo com base em benefícios mútuos (SLONGO; MÜSSNI$\mathrm{CH}, 2005)$. Ainda, justifica-se o estudo em uma perspectiva aplicada pelo fato de que 
os minimercados são empresas pequenas, normalmente familiares e que, em geral, utilizam baixo nível de recursos tecnológicos na gestão das áreas comercial e administrativa. Além de possuírem baixo poder de barganha, concorrem diretamente com grandes redes, as quais concentram participação de mercado e oferecem ao consumidor elementos como variedade e preço baixo em maior escala.

Inicialmente, o artigo apresenta a fundamentação teórica sobre o tema estudado. Em seguida, é descrito o método empregado para se alcançarem os objetivos. Na sequência são apresentadados a análise dos dados e seus resultados, sendo identificado o grau de relacionamento entre minimercados e seus fornecedores, os serviços ao cliente valorizados nesse canal e a influência dos serviços ao cliente no relacionamento estabelecido. Finalmente, são apresentadas as contribuições do estudo em uma perspectiva acadêmica e gerencial.

\section{FUNDAMENTAÇÃO TEÓRICA}

\subsection{SERVIÇOS AO CLIENTE}

Para La Londe e Zinszer (1976), em economias caracterizadas por altas taxas de inflação, juros elevados, recessão e outras adversidades que afetam o mundo dos negócios, bem como em mercados com problemas econômicos e estruturais, os serviços ao cliente constituem uma estratégia capaz de ampliar a oferta dos produtos, por meio de serviços agregados. Em mercados em que a oferta de produtos estrangeiros oriundos de países com forte base e desenvolvimento tecnológico tornou-se intensa, acirrando a concorrência, essa estratégia tende a ser eficaz, principalmente porque está embasada em conceitos de relacionamentos com os clientes (SLONGO, 1996).

Os serviços ao cliente, segundo Heskett, Sasser e Schleninger (1997), são capazes de desenvolver uma cadeia de valor mediante a qual é possível identificar necessidades dos clientes e promover uma oferta que exceda suas expectativas, aumentando, assim, sua satisfação e lealdade. Bowersox e Daugherty (1992) e Banomyong e Supatn (2011) afirmam que o cliente é um ator diferente da empresa, ou seja, um parceiro comercial situado em alguma outra parte da cadeia.

O cliente que está sendo atendido é o foco para o estabelecimento de indicadores de desempenho e de estratégia, sendo este um dos aspectos que contribuem para o reconhecimento do "[...] poder do serviço ao cliente como um meio potencial de diferenciação” (CHRISTOPHER, 2007, p. 43), uma vez que é possível reconhecer nos mercados empresariais a força do serviço ao cliente como um determinante de compra 
(COVA, 2008). Para La Londe e Zinszer (1976) e Daugherty, Kasulis e Richey (2002), as exigências dos consumidores determinam e moldam as atividades do mercado. Fazem, ainda, com que as operações de logística sejam cruciais para se conquistar vantagem competitiva e planejar relacionamentos empresariais sustentáveis, sendo necessárias para se traçarem estratégias de serviços capazes de suprir as expectativas dos clientes, entregando-lhes um produto de valor agregado. De modo geral, usuários finais terão preferência por canais que gerem serviços os quais reduzam sua busca, tempo de espera, armazenagem e outros custos; dessa forma, quanto maior o nível de serviço diferenciado e significativo aos usuários finais, maior será a probabilidade de um intermediário ser incluído em uma estrutura de canal (COUGHLAN et al., 2011).

O serviço ao cliente, definido como "[...] um processo que acontece entre comprador, vendedor e uma terceira parte” (LAMBERT; STERLING, 1986), contempla a realidade das organizações que se colocam na condição de pioneiras em disponibilizar aos clientes um valor agregado aos produtos por meio dos serviços oferecidos. Esse processo, que resulta em valor adicionado, é compartilhado por ambas as partes e deve ser de curto prazo, em uma transação simples, ou de longo prazo, em uma relação contratual. Slongo (1996) faz referência às relações de longo prazo como caracterizadas por situações nas quais os clientes valorizam a manutenção de fornecedores, visto que a substituição eventual implica custos e/ou redução da eficiência em suas operações.

Concomitantemente, em razão da importância da manutenção de relações duradouras, os serviços ao cliente vêm assumindo maior importância para as empresas industriais, visto que sua representatividade é visível, tanto na participação de mercado de um fornecedor industrial quanto na sua lucratividade. Cabe destacar que um mau serviço prestado ao cliente poderá ocasionar custos indesejáveis, como, perda de vendas por falta de produtos ou custos de manutenção de estoques de segurança em decorrência da inconsistência no prazo de entrega do fornecedor (FIGUEIREDO et al., 2007).

\subsection{MARKETING DE RELACIONAMENTO}

Segundo Berry (1983), relacionamentos de troca existem desde a economia de subsistência e envolvem, independentemente de se tratar de uma transação única ou não, benefícios e sacrifícios pelas partes participantes do negócio. Wilson (1995) afirma que os relacionamentos existem desde que os humanos começaram a trocar produtos e serviços e que essas trocas se desenvolviam de maneira natural ao longo do tempo, à medida que compradores e vendedores desenvolviam confiança e amizade apoiadas por produtos e serviços de qualidade. 
As trocas, durante muitos anos, foram consideradas pelos pesquisadores apenas como eventos únicos e discretos e não como relacionamentos constantes ocorridos entre as partes. Trocas discretas ou singulares são caracterizadas por ganhos imediatos, comunicação limitada e relacionamentos pessoais mínimos (MACNEIL, 1980). Ao contrário, trocas relacionais são longitudinais por natureza (PETERSON, 1995), ou seja, ocorrem em razão da continuidade das transações e do histórico da relação, da aproximação das partes e do planejamento futuro previsto para os participantes do negócio.

Segundo Hadjikhani e Laplaca (2013), os estudos em mercados e relações (B2B) dividem-se em três fases: a pré-industrial, industrial e pós-industrial. Nos dois primeiros períodos, o enfoque teórico priorizava as relações transacionais, buscando racionalidade econômica, independência entre os players e maior lucratividade possível em um curto horizonte temporal. Essa abordagem começa a mudar no período pós-industrialização, momento em que a teoria passa a ser comportamental, apontando a importância de relacionamentos com horizonte de médio e longo prazos (HADJIKHANI; LAPLACA, 2013).

Biggemann e Buttle (2012) destacam que a evolução do pensamento em marketing B2B enfatiza a importância do relacionamento e dos benefícios que essa abordagem comportamental proporciona às empresas, o que vai além da redução de custos da oferta; abordagem essa que é basicamente econômica e com ênfase transacional. O sucesso do relacionamento entre empresas é mediado pelo comprometimento, visto que os participantes mantêm relações comerciais ou porque desejam (dedication-based theory) ou porque precisam mantê-las, buscando redução de riscos percebidos (constraint-based theory) (CHANG et al., 2012; GEIGER et al., 2012).

Trocas relacionais bem-sucedidas implicam ganhos mútuos, ou seja, ganhos permanentes no longo prazo, os quais devem compensar os investimentos feitos no relacionamento. Berry (1983), Shani e Chalasani (1992) e Gummesson (2002) visualizam o marketing de relacionamento como um esforço integrado que objetiva identificar, construir e manter uma rede de relacionamento, a fim de conseguir benefícios mútuos em um longo período de tempo.

Segundo Costa e Barreiros (2013), a abordagem relacional permite aos parceiros identificarem competências e aprimorarem modelos de gestão, pois leva ao desenvolvimento de know how, fonte de inovação para os negócios, ao permitir o conhecimento de best practices entre os parceiros que proporcionam identificar e aprimorar competências. Essa abordagem amplia a capacidade competitiva das partes envolvidas, pois além de reduzir custos operacionais e de inovação, permite maior flexibilidade, 
ciclos de produção e comercialização mais curtos e orientação para o cliente, elementos essenciais para atuar em mercados de concorrência crescente (PATIL; PATIL, 2014).

Autores como Morgan e Hunt (1994) e Morgan (2000) apontam como cerne do relacionamento o comprometimento e afirmam que o desenvolvimento do comprometimento, da confiança e de uma efetiva cooperação no marketing de relacionamento depende do entrelaçamento de três fatores principais: relações que proporcionem benefícios econômicos - as quais criam cooperação eficaz e preservam a relação, recursos compartilhados entre as partes a fim de se alcançarem vantagem competitiva e envolvimento social entre as partes, encorajando a cooperação no canal.

Para Stern et al. (2002), relacionamentos de longo prazo são embasados em confiança e comprometimento, cuja essência do comprometimento é estabilidade e sacrifício. Comprometer-se implica predisposição a efetuar sacrifícios de curto prazo, a fim de se alcançarem benefícios consideráveis ao longo do relacionamento. Essa orientação parte do pressuposto de que o relacionamento durará o suficiente para que as partes alcancem seus objetivos e benefícios (ANDERSON; WEITZ, 1992). Se um relacionamento é eficaz, automaticamente se cria uma barreira significativa à mudança de uma das partes, e o desejo de permanecer no relacionamento é intensificado. Dwyer, Schurr e Oh (1987) apontam, ainda, que a expectativa de um elevado custo de mudança por uma das partes origina o interesse em manter um relacionamento de qualidade. Nesse sentido, Wilson (1995) destaca que o comprometimento assume que o relacionamento trará valor futuro ou benefícios aos parceiros ao longo do tempo.

Para fins deste estudo, optou-se pela utilização do modelo de Wilson e Vlosky (1997) para a mensuração do marketing de relacionamento, modelo este constituído por atributos indicadores de marketing de relacionamento presentes nos estudos de diversos autores, como Morgan e Hunt (1994), Wilson (1995) e Morgan (2000).

\subsubsection{O Modelo de Wilson e Vlosky (1997)}

A disseminação da importância dos relacionamentos fez com que pesquisadores direcionassem esforços no sentido de criar modelos que permitissem mensurar o marketing de relacionamento na gestão de canais de marketing. Nesse sentido, Wilson e Vlosky (1997) realizaram uma pesquisa na indústria de madeira e seus derivados nos Estados Unidos, a fim de medirem e analisarem o relacionamento estabelecido no canal de marketing, investigando a estrutura de parcerias em contraposição aos relacionamentos tradicionais, descritos por Macneil (1978) como transações discretas. 
A escala para a mensuração de marketing de relacionamento proposta por Wilson e Vlosky (1997) é composta de um conjunto de seis variáveis latentes, as quais desempenham papel determinante na diferenciação entre trocas convencionais e relacionamentos de parceria. Essas variáveis latentes são: dependência, nível de comparação de alternativas, investimentos específicos no relacionamento, partilha de informações, confiança e comprometimento.

Os resultados da pesquisa de Wilson e Vlosky (1997) são coniventes com os aportes teóricos de outros pesquisadores (MORGAN; HUNT, 1994; DWYER; SCHURR, OH, 1987), os quais colocam atividades de interação, dependência mútua, desenvolvimento de confiança e comprometimento como fundamentais para o estabelecimento de parcerias em um canal de marketing. Desse modo, o constructo apresentado pelos autores, além de permitir a interação de outros modelos de pesquisa, apresenta-se como instrumento de pesquisa válido para mensurar o marketing de relacionamento entre empresas.

No Brasil, essa mesma escala foi aplicada inicialmente por Viana (1999) no setor metal-mecânico gaúcho, que realizou a tradução da escala por meio do método de tradução reversa. A partir desse método, a escala original foi traduzida para o português e posteriormente para o inglês novamente, a fim de verificar sua legitimidade. Essa escala também foi utilizada por outros autores em distintos segmentos, revelando-se um instrumento consistente para a verificação da intensidade do relacionamento. Entre os autores citam-se: Daronco (2001), Müssnich (2002), De Toni (2003), Klein (2003), Gomes et al. (2010), Morais (2010), entre outros.

Ao referirem-se aos serviços ao cliente, Innis e La Londe (1994) e Berry e Parasuraman (1991) sustentam que a oferta complementar de serviços é capaz de fornecer benefícios agregando valor e gerando ganhos significativos à cadeia. Para Stern et al. (2002), o conceito de valor fornecido, os benefícios e a satisfação constante, oriundos da utilidade que um parceiro fornece ao outro, está atrelados à escassez de alternativas no que diz respeito a fornecedores possíveis. Segundo os autores, quanto maior o benefício ofertado e menor as fontes alternativas, maior a dependência no canal de marketing.

Grönroos (2000) salienta que quanto mais valor o serviço ofertado gera, maior o esforço e a disposição das pessoas em empregarem recursos para obtê-lo. Dessa forma, como a oferta complementar de serviços cria valor adicionado, objetiva-se verificar pelas hipóteses $\mathrm{H} 1$ e $\mathrm{H} 2$ se, no canal objeto de estudo, os serviços ao cliente são capazes de influenciar as dimensões de marketing de relacionamento: 
H1: A oferta de serviços ao cliente influencia o sentimento de dependência dos varejistas de pequeno porte em relação aos fornecedores.

H2: Os serviços ao cliente, ofertados pelo fornecedor, influenciam o investimento feito no relacionamento pelos varejistas.

Wilson (1995) e Abbade e Noro (2012) salientam que os relacionamentos se tornam estratégicos e que o processo de desenvolvimento do relacionamento é acelerado à medida que as empresas lutam para criar relacionamentos e alcançar suas metas. Müssnich (2002) cita que o nível de comparação do atual parceiro com os demais disponíveis no mercado tende a ser positivo para aqueles que proverem maior valor agregado às transações e esforço com reflexos na qualidade dos serviços e, por consequência, na confiança desenvolvida entre as partes. Considerando Wilson (1995), Abbade e Noro (2012) e Müssnich (2002), surge a terceira hipótese do estudo:

H3: Os serviços ao cliente influenciam a avaliação de alternativas por parte dos varejistas.

Dwyer, Schurr e Oh (1987) colocam a comunicação e a troca de informações como fundamentais para o desenvolvimento do relacionamento, principalmente em fase de exploração, em que o envolvimento das partes no negócio está em processo de evolução. Zeithaml, Parasuraman e Berry (1985), ao discorrerem sobre a qualidade dos serviços, apontam a comunicação como dimensão importante da empatia, relacionada à capacidade de compreensão das reais necessidades do parceiro e à troca de informações. Portanto, propõe-se a seguinte hipótese:

H4: Os serviços ao cliente exercem influência na troca de informações ocorridas entre os varejistas e seus fornecedores.

Relacionamentos de longo prazo permeados por altos níveis de confiança levam ao comprometimento (MORGAN; HUNT, 1994). O comprometimento descrito como o desejo de continuidade da relação (DWYER; SCHURR E OH, 1987; WILSON, 1995) é decorrente de um processo que envolve cooperação mútua e confiança depositada nas ações do parceiro.

Considerando que a oferta complementar de serviços em um canal de marketing pode proporcionar vantagem competitiva, bem como relacionamentos de longo prazo podem oferecer vantagens à medida que contribuem para a diferenciação da 
oferta (DWYER; SCHURR E OH, 1987; DEMO; ROZZETT, 2013), torna-se oportuno investigar o impacto exercido pelos serviços ao cliente na formação da confiança e do comprometimento no canal de marketing, bem como o impacto exercido no marketing de relacionamento considerando-se todas as dimensões que o compõem. Para tanto, foram definidas as seguintes hipóteses:

H5: Os serviços ao cliente exercem influência no sentimento de confiança depositado nos fornecedores.

H6: Os serviços ao cliente ofertados influenciam no comprometimento dos varejistas com seus fornecedores.

H7: Os serviços ao cliente exercem influência no marketing de relacionamento.

\section{MÉTODO}

No estudo foi desenvolvida uma survey composta por duas etapas. A primeira teve como propósito ajustar a escala de marketing de relacionamento de Wilson e Vlosky (1997) e identificar os serviços ao cliente valorizados pelos gestores de minimercados. Para tanto, uma pesquisa exploratória e qualitativa foi realizada por meio de entrevistas em profundidade com gestores varejistas escolhidos por julgamento, adotando-se como critério de escolha a experiência destes no segmento. As entrevistas foram realizadas individualmente, utilizando-se um roteiro semiestruturado composto por cinco perguntas abertas.

Já a segunda etapa consistiu em um levantamento quantitativo e descritivo, o qual teve como propósito avaliar o grau de relacionamento estabelecido no canal de marketing, a importância dos serviços ao cliente e a sua influência no marketing de relacionamento. O grau de relacionamento foi mensurado por meio das variáveis que sustentam as seis dimensões propostas no modelo de Wilson e Vlosky (1997) (subseção 2.2.1), enquanto a influência dos serviços ao cliente no relacionamento foi testada por intermédio das hipóteses propostas no estudo, que estão apresentadas no Quadro 1.

Quadro 1 - Hipóteses de Pesquisa

\begin{tabular}{|l|l|}
\hline HIPÓTESES DE PESQUISA & PRINCIPAIS AUTORES \\
\hline $\begin{array}{l}\text { H1: A oferta de serviços ao cliente influencia o sentimento de } \\
\text { dependência dos varejistas de pequeno porte em relação aos } \\
\text { fornecedores. }\end{array}$ & $\begin{array}{l}\text { Berry e Parasuraman (1991), Innis e } \\
\text { La Londe (1994), Grönroos (2000) e } \\
\text { Stern et al. (2002). }\end{array}$ \\
\hline
\end{tabular}




\begin{tabular}{|c|c|}
\hline $\begin{array}{l}\text { H2: Os serviços ao cliente, ofertados pelo fornecedor, influen- } \\
\text { ciam o investimento feito no relacionamento pelos varejistas. }\end{array}$ & $\begin{array}{l}\text { Berry e Parasuraman (1991), Innis e } \\
\text { La Londe (1994), Grönroos (2000) e } \\
\text { Stern et al. (2002). }\end{array}$ \\
\hline $\begin{array}{l}\text { H3: Os serviços ao cliente influenciam a avaliação de alternati- } \\
\text { vas por parte dos varejistas. }\end{array}$ & Wilson (1995) e Müssnich (2002). \\
\hline $\begin{array}{l}\text { H4: Os serviços ao cliente exercem influência na troca de infor- } \\
\text { mações ocorridas entre os varejistas e seus fornecedores. }\end{array}$ & $\begin{array}{l}\text { Zeithaml, Parasuraman e Berry (1985) } \\
\text { e Dwyer, Schurr e Oh (1987). }\end{array}$ \\
\hline $\begin{array}{l}\text { H5: Os serviços ao cliente exercem influência no sentimento de } \\
\text { confiança depositada nos fornecedores. }\end{array}$ & $\begin{array}{l}\text { Dwyer, Schurr e Oh (1987), Morgan e } \\
\text { Hunt (1994), Wilson (1995) e Demo e } \\
\text { Rozzett (2013). }\end{array}$ \\
\hline $\begin{array}{l}\text { H6: Os serviços ao cliente ofertados influenciam o comprometi- } \\
\text { mento dos varejistas com seus fornecedores. }\end{array}$ & $\begin{array}{l}\text { Dwyer, Schurr e Oh (1987), Morgan e } \\
\text { Hunt (1994) e Wilson (1995). }\end{array}$ \\
\hline $\begin{array}{l}\text { H7: Os Serviços ao Cliente exercem influência no marketing de } \\
\text { relacionamento. }\end{array}$ & $\begin{array}{l}\text { Dwyer, Schurr e Oh (1987), Morgan e } \\
\text { Hunt (1994) e Wilson (1995). }\end{array}$ \\
\hline
\end{tabular}

Fonte: os autores.

A população da pesquisa foi constituída por minimercados, lojas de autosserviço que possuem entre um a quatro check-outs, juridicamente constituídos e ativos, estabelecidos em uma cidade gaúcha de médio porte. Os dados da população foram obtidos com três empresas locais, as quais fornecem produtos a esse segmento do varejo. Após triagem foi contemplada uma relação composta por 187 varejistas, visto que todas as empresas foram visitadas; entretanto, das relacionadas, 156 foram passíveis de investigação por se enquadrarem no perfil de autosserviço. Ocorreu o retorno de 132 questionários, o equivalente a 84,62\% do total de minimercados investigados, percentual significativo, uma vez que Malhotra (2001) sugere como 15\% um bom índice de retorno para pesquisas que não incluem incentivos diretos.

A coleta de dados ocorreu por meio da aplicação de um questionário composto por 30 variáveis para a mensuração do marketing de relacionamento e 23 itens relacionados a serviços ao cliente. As escalas adotadas na pesquisa são do tipo intervalar de cinco pontos, oscilando de "discordo totalmente" a "concordo totalmente" para a mensuração do marketing de relacionamento, e de "muito pequena” a "muito grande" para a mensuração da ênfase atribuída pelo fornecedor aos serviços ao cliente. O questionário foi respondido por escrito e sem a presença do entrevistador.

Utilizaram-se para a análise, técnicas univariadas, as quais incluíram o cálculo de médias e desvio padrão, e técnicas multivariadas, como análise de regressão múltipla (HAIR JÚNIOR et al., 2005). Para a análise de regressão múltipla foi utilizado o procedimento enter, o qual foi escolhido por melhor atender ao objetivo do estudo, além de ser considerado o mais adequado considerando-se o número de observações existentes (HAIR JÚNIOR et al., 2005). 
A avaliação da consistência interna das dimensões que compõem o modelo de marketing de relacionamento e o conjunto de serviços ao cliente foram verificados por meio do Alpha de Cronbach, como pode ser observado na Tabela 1.

Tabela 1 - Confiabilidade - marketing de relacionamento e serviços ao cliente

\begin{tabular}{ll}
\hline Marketing de Relacionamento & Alpha Cronbach \\
\hline Dependência do Fornecedor & 0,533 \\
Nível de Comparação com Fornecedores Alternativos & 0,603 \\
Investimentos no Relacionamento & 0,630 \\
Troca de Informações & 0,721 \\
Confiança & 0,737 \\
Comprometimento & 0,846 \\
\hline Serviços ao Cliente & Alpha Cronbach \\
\hline Conjunto de Serviços ao Cliente & $\mathbf{0 , 9 2 3}$ \\
\hline
\end{tabular}

Fonte: os autores.

\section{RESULTADOS}

Os resultados obtidos são apresentados em quatro etapas: na primeira, é demonstrada a caracterização da amostra. Na segunda, são apresentados, por meio de análises descritivas univariadas, o nível de relacionamento existente entre os minimercados e seus fornecedores e a ênfase atribuída pelos fornecedores aos serviços ao cliente, sob a ótica dos varejistas. Na terceira aborda-se a percepção dos varejistas no que se refere aos serviços agregados, e a quarta e última etapa trata da verificação das hipóteses de pesquisa (Quadro 1).

\subsection{DESCRIÇÃO DA AMOSTRA}

Dos 132 questionários que retornaram o contato, foram validados 129 para fins de investigação. Os minimercados localizam-se, em sua maioria, em bairros da cidade, e por serem empresas de pequeno porte, trabalham com um mix de produtos reduzido, ajustado às principais demandas dos clientes. Os dados levantados indicam, ainda, que $72,87 \%$ das respostas estão embasadas em relacionamentos solidificados, existentes há três anos ou mais, os quais podem ser considerados duradouros. Esse resultado proporciona maior respaldo ao estudo de marketing de relacionamento no canal pesquisado. 
Entre os minimercados investigados, observa-se que a maioria é composta por apenas um ou dois check-outs, com 50,39\% e 31,01\%, respectivamente. Dos casos validados, $60 \%$ possuem um faturamento anual bruto de $\mathrm{R} \$ 60.000,00$, e apenas $11 \%$ possuem um faturamento acima de R\$ 500.000,00. Entre os fornecedores apontados como estratégicos figuram os de produtos de higiene e limpeza, bebidas, carnes e grãos.

\subsection{GRAU DE RELACIONAMENTO}

De acordo com a proposta de Wilson e Vlosky (1997), seis dimensões desempenham papel determinante na diferenciação entre relacionamentos tradicionais e trocas relacionais, são elas: dependência do fornecedor, nível de comparação com fornecedores alternativos, investimentos no relacionamento, troca de informações, confiança e comprometimento. Assim, a percepção dos varejistas frente a cada uma das referidas dimensões foi mensurada, e, por meio da média geral e do desvio padrão obtido, pode-se verificar o grau de relacionamento estabelecido no canal investigado (Tabela 2). Destaca-se que o resultado exposto é reflexo de todas as variáveis que compõem cada dimensão, consideradas simultaneamente.

Tabela 2 - Grau de relacionamento

\begin{tabular}{lll}
\hline Dimensões do marketing de relacionamento & Média geral & Desvio padrão \\
\hline 1. Dependência do fornecedor & 2,96 & 0,763 \\
2. Nível de comparação com fornecedores alternativos & 2,92 & 0,539 \\
3. Investimentos no relacionamento & 3,08 & 0,837 \\
4. Troca de informações & 2,63 & 1,200 \\
5. Confiança & 3,08 & 0,786 \\
6. Comprometimento & 4,03 & 0,757 \\
\hline
\end{tabular}

Fonte: os autores.

Considerando-se a dimensão dependência do fornecedor, os principais resultados encontrados demonstram que os varejistas consideraram os fornecedores selecionados estratégicos para o futuro dos negócios, porém foi identificado que o fornecedor mais importante indicado pelos respondentes pode ser facilmente substituído, sem grandes prejuízos aos pequenos varejos. Esse resultado indica certa fragilidade quanto à dependência mútua entre as partes, sinalizando que a relação de parceria, a qual envolve cooperação entre os participantes, apresenta-se vulnerável.

Em relação à dimensão nível de comparação com fornecedores alternativos, os resultados apontaram que o fornecedor escolhido pelos varejistas é o que apresentar 
melhor nível de qualidade, quando comparado aos demais fornecedores. Entretanto, esta não é vista como uma dimensão de maior importância, considerando que 62,79\% dos varejistas acreditam que o relacionamento estabelecido com seus fornecedores atende às suas expectativas, mas sem ter maior impacto na sua satisfação.

Na dimensão investimentos no relacionamento, os resultados indicaram que um rompimento na relação com os principais fornecedores traria transtornos para os minimercados. Identificou-se que os gestores de minimercados realizam investimentos razoáveis no relacionamento, ou seja, buscam preservar o relacionamento cooperando com seus fornecedores e resistem a atraentes opções de curto prazo ofertadas por fornecedores alternativos; isso ocorre em virtude de benefícios advindos no longo prazo com os parceiros existentes. Nessa dimensão, ainda verificou-se que o custo total de mudança dos varejistas para outro fornecedor não seria tão significativo, caso essa fosse sua opção.

Quanto à troca de informações, constata-se que os varejistas não trocam muitas informações com seus fornecedores. Esse resultado vincula-se ao fato de que os relacionamentos investigados neste estudo são, em sua maioria, existentes há três anos ou mais, podendo ser considerados sólidos. Dwyer, Schurr e Oh (1987) comentam que a comunicação e a troca de informações estratégicas ocorrem em maior escala na fase de exploração do relacionamento e que, com o decorrer do tempo e com o envolvimento das partes no negócio, a necessidade de uma constante troca de informações já não é tão necessária.

Em relação à confiança, a média geral de 3,08, para uma escala de cinco pontos sinaliza que os varejistas não depositam um alto grau de confiança em seus fornecedores, quando se compara à dimensão comprometimento. O comprometimento apresentou média de 4,03, sendo a mais alta de todo o constructo. Stern et al. (2002) colocam a estabilidade e o sacrifício como essências do comprometimento, o qual é embasado nos benefícios futuros advindos da parceria formada. Os resultados, portanto, demonstram que os varejistas se sentem altamente comprometidos com seus fornecedores, embora não expressem muita confiança nesses parceiros.

\subsection{SERVIÇOS AO CLIENTE}

A partir dos itens de serviços gerados por meio da pesquisa qualitativa, foi possível determinar a importância atribuída pelos varejistas da amostra no que se refere aos serviços disponibilizados pelos fornecedores. Na Tabela 3 é apresentada a síntese dos resultados. 
Tabela 3 - Classificação dos Itens de Serviços ao Cliente Gerados na Pesquisa Qualitativa

\begin{tabular}{|c|c|c|c|}
\hline & $\begin{array}{l}\text { Itens de serviços ao cliente } \\
\text { Alpha de Cronbach }=0,923\end{array}$ & Média** & $\begin{array}{l}\text { Desvio } \\
\text { padrão }\end{array}$ \\
\hline 12 & Cumprimento do prazo de entrega do pedido & 4,14 & 1,058 \\
\hline 23 & Frequência de contatos dos vendedores do fornecedor com os clientes & 3,86 & 1,115 \\
\hline 19 & Disponibilidade de estoques & 3,82 & 1,190 \\
\hline 20 & Condições para agilizar o processamento e a expedição de pedidos & 3,74 & 1,137 \\
\hline 18 & Amplitude da linha de produtos oferecidos & 3,59 & 1,200 \\
\hline 11 & $\begin{array}{l}\text { Manutenção de estoques capazes de atender aos pedidos dos clientes por } \\
\text { completo }\end{array}$ & 3,45 & 1,320 \\
\hline 2 & Atendimento a pedidos extras ou de urgência & 3,40 & 1,365 \\
\hline 13 & Agilidade na tomada de providências em casos de reclamação do cliente & 3,35 & 1,246 \\
\hline 15 & Agilidade no retorno das solicitações do cliente & 3,33 & 1,234 \\
\hline 3 & Fornecimento de informações sobre o andamento do pedido & 3,18 & 1,318 \\
\hline 8 & $\begin{array}{l}\text { Inovação de produtos, visando melhorar o desempenho operacional do clien- } \\
\text { te }\end{array}$ & 3,17 & 1,341 \\
\hline 6 & Assistência prestada ao cliente na composição do pedido & 3,13 & 1,321 \\
\hline 21 & $\begin{array}{l}\text { Condições em viabilizar mudanças de datas de entrega previamente acorda- } \\
\text { das }\end{array}$ & 3,11 & 1,303 \\
\hline 14 & $\begin{array}{l}\text { Disponibilidade de alternativas de descontos de preço por quantidade ou por } \\
\text { pagamentos antecipados }\end{array}$ & 3,03 & 1,395 \\
\hline 9 & $\begin{array}{l}\text { Desenvolvimento de produtos específicos para atender às necessidades de } \\
\text { determinados clientes }\end{array}$ & 3,02 & 1,367 \\
\hline 17 & Opções de embalagens diferenciadas para os produtos oferecidos & 3,02 & 1,360 \\
\hline 10 & Treinamento de vendedores e representantes para o atendimento dos clientes & 3,01 & 1,474 \\
\hline 22 & Desenvolvimento de parcerias (acordos de cooperação) com os clientes & 3,01 & 1,325 \\
\hline 16 & Agilidade na troca de produtos & 2,97 & 1,432 \\
\hline 4 & $\begin{array}{l}\text { Disponibilidade de um promotor para a organização e a manutenção dos } \\
\text { produtos }\end{array}$ & 2,61 & 1,520 \\
\hline 1 & $\begin{array}{l}\text { Treinamento ou apoio ao cliente para o bom uso e manuseio do produto } \\
\text { fornecido }\end{array}$ & 2,61 & 1,312 \\
\hline 5 & $\begin{array}{l}\text { Fornecimento de manuais técnicos e informativos sobre a manutenção de } \\
\text { produtos }\end{array}$ & 2,39 & 1,263 \\
\hline 7 & $\begin{array}{l}\text { Promoção de encontros ou seminários, a fim de se instruirem ou melhorarem } \\
\text { conhecimentos dos clientes quanto ao bom uso do produto oferecido }\end{array}$ & 2,27 & 1,334 \\
\hline
\end{tabular}

Fonte: os autores.

Os resultados apresentados na Tabela 3 demonstram que no canal de marketing investigado, cinco serviços receberam atenção especial por parte dos fornecedores: cumprimento dos prazos de entrega, frequência de contato dos vendedores, disponibilidade de estoques, condições para agilizar o processamento e a expedição de pedidos e amplitude da linha de produtos oferecidos, os quais obtiveram as maiores médias. A grande maioria 
dos serviços oscilou entre as médias 2,61 e 3,45, e apenas os itens fornecimento de manuais técnicos e informativos sobre manutenção de produtos e promoção de encontros ou seminários, a fim de instruir ou melhorar conhecimentos dos clientes quanto ao bom uso do produto oferecido obtiveram médias abaixo de 2,5, demonstrando a pouca importância atribuída pelos fornecedores a esses serviços relacionados à informação.

\subsection{INFLUÊNCIA DOS SERVIÇOS AO CLIENTE NO MARKETING DE RELACIONAMENTO}

Para se avaliar a influência do conjunto de serviços ao cliente no marketing de relacionamento realizou-se uma análise de regressão múltipla. Entretanto, como uma das preocupações dos pesquisadores foi sobre a existência de multicolinearidade entre as variáveis, examinaram-se, inicialmente, o fator de variância (VIF) e a tolerância (quantia de variabilidade da variável independente selecionada não explicada pelas outras variáveis independentes). Segundo Hair et al. (2005), a multicolinearidade ocorre quando qualquer variável independendente é altamente correlacionada a um conjunto de outras variáveis independentes, podendo influenciar as estimativas dos coeficientes de regressão. Neste estudo, o fator de variância e a tolerância atendem às recomendações de Hair et al. (2005), ou seja, o menor valor encontrado para a tolerância foi de 0,392, e o maior valor encontrado para a VIF foi de 3,643.

Para se avaliar a influência dos serviços ao cliente no marketing de relacionamento, inicialmente verificou-se a relação existente entre cada dimensão de marketing de relacionamento com cada variável de serviços ao cliente. Para tanto, foi realizada uma análise de regressão múltipla, a qual envolveu os seguintes aspectos: variáveis dependentes, compostas pelas dimensões de marketing de relacionamento, e variáveis independentes, sendo o conjunto de serviços ao cliente, composto por 23 itens (Tabela 4).

Os valores $\beta$ (Beta) padronizados identificam a força das relações causais do modelo, indicando o quanto a variável dependente é modificada quando o valor da variável independente varia em uma unidade. Assim, as estatísticas geradas apresentam o comportamento do modelo, considerando como variável dependente cada dimensão de marketing de relacionamento. Neste estudo, optou-se por considerar o $\mathrm{R}^{2}$ e não o coeficiente de $\mathrm{R}^{2}$ Ajustado para a explicação do modelo. A escolha está atrelada ao tamanho da amostra e ao número de variáveis independentes do estudo, e ao fato de que o $\mathrm{R}^{2}$ Ajustado considera a proporção de observações e o número de variáveis independentes, conforme equação a seguir: 
$\mathrm{R}^{2}$ Ajustado $=1-\left(1-\mathrm{R}^{2}\right)\left[\frac{\mathrm{n}-1}{\mathrm{n}-\mathrm{p}-1}\right]$

Em que: $\mathrm{n}$ = tamanho da amostra;

$\mathrm{p}=\mathrm{n}$. de variáveis independentes.

Hair Júnior et al. (2005) comentam que o $\mathrm{R}^{2}$ Ajustado, embora tenha a mesma interpretação do $\mathrm{R}^{2}$, torna-se menor quando há menos observações por variável independente, podendo, nesse caso, distorcer os resultados. Dessa forma, considerando o tamanho da amostra e o número de variáveis independentes, optou-se pelo uso $\mathrm{R}^{2}$, já que o $\mathrm{R}^{2}$ Ajustado é particularmente útil e considerado essencial para a comparação de equações que apresentam diferentes tamanhos de amostra e diferentes números de variáveis independentes em cada modelo.

Tabela 4 - Serviç̧os ao cliente presentes nas dimensões de marketing de relacionamento

\begin{tabular}{|c|c|c|c|c|c|c|c|}
\hline Marketing de Relacionamento & 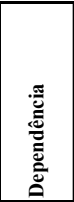 & 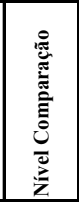 & 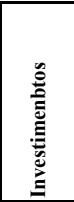 & 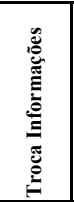 & 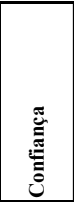 & 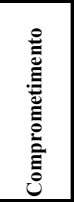 & 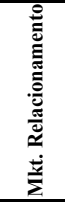 \\
\hline $\begin{array}{l}\text { Treinamento ou apoio ao cliente para o bom uso e manuseio do produto } \\
\text { fornecido }\end{array}$ & - & $0,404 *$ & $0,055^{*}$ & $0,462 *$ & $0,527 *$ & $0,353 *$ & $0,554^{*}$ \\
\hline Atendimento a pedidos extras ou de urgência & - & $0,214 *$ & $0,138^{*}$ & $0,443 *$ & $0,541^{*}$ & $0,278 *$ & $0,469^{*}$ \\
\hline Fornecimento de informações sobre o andamento do pedido & - & $0,107 *$ & $0,291^{*}$ & - & 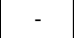 & ـ & 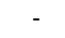 \\
\hline $\begin{array}{l}\text { Disponibilidade de um promotor para organização e manutenção } \\
\text { dos produtos }\end{array}$ & - & - & - & - & $0,037^{*}$ & - & - \\
\hline $\begin{array}{l}\text { Fornecimento de manuais técnicos e informativos sobre manutenção de } \\
\text { produtos }\end{array}$ & $0,481 *$ & - & - & - & - & $0,146^{*}$ & - \\
\hline Assistência prestada ao cliente na composição do pedido & $0,085^{*}$ & $0,176^{*}$ & - & - & - & - & - \\
\hline $\begin{array}{l}\text { Promoção de encontros, ou seminários a fim de instruir ou melhorar } \\
\text { conhecimentos dos clientes quanto ao bom uso do produto oferecido }\end{array}$ & - & $0,036^{*}$ & $0,117 *$ & $0,090^{*}$ & - & $0,042 *$ & $0,005^{*}$ \\
\hline $\begin{array}{l}\text { Inovação de produtos, com vistas a melhorar o desempenho operacional } \\
\text { do cliente }\end{array}$ & $0,315^{*}$ & - & - & $0,148^{*}$ & $0,253^{*}$ & $0,201 *$ & $0,228^{*}$ \\
\hline $\begin{array}{l}\text { Desenvolvimento de produtos específicos para atender necessidades de } \\
\text { determinados clientes }\end{array}$ & - & - & $0,065^{*}$ & - & - & - & - \\
\hline $\begin{array}{l}\text { Treinamento de vendedores e representantes para o atendimento dos } \\
\text { clientes }\end{array}$ & - & $0,287 *$ & - & $0,294 *$ & & & $0,006^{*}$ \\
\hline $\begin{array}{l}\text { Manutenção de estoques capazes de atender aos pedidos dos clientes por } \\
\text { completo }\end{array}$ & $0,048^{*}$ & $0,188^{*}$ & $0,110^{*}$ & - & - & $0,060 *$ & $0,019 *$ \\
\hline Cumprimento do prazo de entrega do pedido & $0,283 *$ & - & - & 0,087 & 0,293 & 0,573 & $0,259^{*}$ \\
\hline Agilidade na tomada de providencias em casos de reclamação & 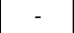 & $0,314 *$ & $0,422 *$ & $0,173^{*}$ & - & - & $0,151 *$ \\
\hline $\begin{array}{l}\text { Disponibilidade de alternativas de descontos de preço por quantidade, ou } \\
\text { por pagamentos antecipados }\end{array}$ & $0,024 *$ & - & - & - & $0,597 *$ & $0,025^{*}$ & - \\
\hline licitações do cliente & - & - & - & - & - & - & \\
\hline Agilidade na troca de produtos & - & $0,424 *$ & - & - & - & - & - \\
\hline Opções de embalagens diferenciadas para os produtos oferecidos & $0,320 *$ & $0,244 *$ & $0,382 *$ & $0,453^{*}$ & - & $0,201 *$ & $0,496^{*}$ \\
\hline dutos oferecidos & $0,084 *$ & $0,021 *$ & $0,173^{*}$ & - & $0,112 *$ & - & $0,036^{*}$ \\
\hline Dis & $0,108 *$ & - & 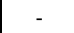 & - & - & - & - \\
\hline Condi & $0,298 *$ & - & $0,197 *$ & - & $0,005^{*}$ & $0,085^{*}$ & $0,089^{*}$ \\
\hline $\begin{array}{l}\text { Condições em viabilizar mudanças de datas de entrega previamente } \\
\text { acordadas }\end{array}$ & - & - & & - & $0,171 *$ & $0,005 *$ & 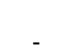 \\
\hline ordos de & - & - & - & $0,462 *$ & $0,037 *$ & $0,637 *$ & $0,310^{*}$ \\
\hline Freqüência de contatos dos vendedores do fornecedor com o & - & $0,148 *$ & $0,144 *$ & - & $0,200^{*}$ & $0,145^{*}$ & $0,138^{*}$ \\
\hline
\end{tabular}

Fonte: os autores.

Notas: (*) Valores de $\beta$ significativos a 0,05.(-) itens de serviços não significativos no modelo ( $p>0,05)$. 
Considerando-se as hipóteses da pesquisa (Quadro 1), a significância das relações causais entre serviços ao cliente e dimensões do marketing de relacionamento foi verificada, e os resultados são apresentados na Tabela 5.

\begin{tabular}{|c|c|c|c|}
\hline \multicolumn{4}{|c|}{ Relação Causal } \\
\hline$\overline{\mathrm{H} 1}$ & Serviços ao cliente & Dependência & $\mathbf{R}^{2}=\mathbf{0 , 5 1 0}$ \\
\hline $\mathrm{H} 2$ & Serviços ao cliente & Nível de comparação & $\mathbf{R}^{2}=\mathbf{0 , 4 2 1}$ \\
\hline $\mathrm{H} 3$ & Serviços ao cliente & Investimentos no relacionamento & $\mathbf{R}^{2}=\mathbf{0 , 5 4 6}$ \\
\hline $\mathrm{H} 4$ & Serviços ao cliente & Troca de informações & $\mathbf{R}^{2}=0,462$ \\
\hline H5 & Serviços ao cliente & Confiança & $\mathbf{R}^{2}=\mathbf{0 , 6 3 6}$ \\
\hline H6 & Serviços ao cliente & Comprometimento & $\mathbf{R}^{2}=\mathbf{0 , 5 1 7}$ \\
\hline $\mathrm{H} 7$ & Serviços ao cliente & Marketing de relacionamento & $\mathbf{R}^{2}=0,498$ \\
\hline
\end{tabular}

Fonte: os autores.

A hipótese 1 afirmava que a oferta de serviços ao cliente influencia o sentimento de dependência dos varejistas de pequeno porte em relação aos fornecedores. Pontualmente, verificou-se que o conjunto de serviços ao cliente explica $51 \%$ da variação da dependência; os serviços fornecimento de manuais $(\beta=0,481)$, opções de embalagens diferenciadas ( $\beta=0,320)$, inovação de produtos $(\beta=0,315)$, condições em agilizar a expedição dos pedidos $(\beta=0,298)$ e cumprimento dos prazos de entrega $(\beta=0,283)$ exercem maior influência ou impacto na dependência dos minimercados em relação aos fornecedores. Stern et al. (2002) afirmam que, em canais de marketing, poder, conflito e dependência permeiam as relações de troca entre os membros, argumentando que a dependência surge da necessidade e da importância que um parceiro representa para o outro.

A hipótese 2 contempla que os serviços ao cliente ofertados pelo fornecedor influenciam o nível de comparação feito pelos varejistas para avaliarem seus fornecedores. Com base nos dados, pode-se verificar que os serviços relacionados à agilidade na troca de produtos $(\beta=0,424)$, ao treinamento ou apoio ao cliente para o bom uso e manuseio do produto fornecido $(\beta=0,404)$, à agilidade na tomada de providências em casos de reclamação ( $\beta=0,314)$ e ao treinamento de vendedores/representantes para o atendimento dos clientes $(\beta=0,287)$ constituem as principais dimensões distintivas entre fornecedores utilizados e fornecedores alternativos, ou seja, tais itens de serviços exercem maior influência nessa variável dependente. Esses resultados demonstram os riscos que os fornecedores atuais correm se não oferecerem esses serviços, uma vez que, conforme resultados anteriormente apresentados, os minimercados não visualizam muitas dificuldades em trocar de fornecedores. 
A hipótese 3 infere que os serviços ao cliente influenciam no investimento em relacionamento por parte dos varejistas. De acordo com os resultados, observa-se que o conjunto de serviços ao cliente explica 54,6\% da variância da dimensão investimentos no relacionamento. Os serviços como agilidade na tomada de providências em caso de reclamação dos clientes $(\beta=0,422)$, opções de embalagens diferenciadas para os produtos oferecidos ( $\beta=0,382$ ) e fornecimento de informações sobre o andamento do pedido $(\beta=0,291)$ assumem importância na previsão da variável dependente. Em contrapartida, serviços como treinamento ou apoio ao cliente para o bom uso e manuseio do produto $(\beta=0,055)$, desenvolvimento de produtos específicos $(\beta=0,065)$ e manutenção de estoques $(\beta=0,110)$ apresentam menor influência na decisão dos varejistas em investirem mais no relacionamento.

A hipótese 4 destaca que os serviços ao cliente exercem influência na troca de informações ocorrida entre os varejistas e seus fornecedores, permitindo verificar que $46,2 \%$ da variação da troca de informações pode ser explicada pelo conjunto de serviços ao cliente. Os valores de $\beta$ padronizados para os serviços treinamento ou apoio ao cliente para o bom uso e manuseio do produto fornecido $(\beta=0,462)$, desenvolvimento de parcerias com os clientes $(\beta=0,462)$, opções de embalagens diferenciadas $(\beta=$ $0,453)$, atendimento de pedidos extras ou de urgência $(\beta=0,443)$ e treinamento de vendedores e representantes para o atendimento dos clientes $(\beta=0,294)$ apresentam maior impacto na variação da dimensão de variáveis referentes à troca de informações dentro do constructo marketing de relacionamento.

A hipótese 5 afirma que os serviços ao cliente exercem influência no sentimento de confiança depositada nos fornecedores. Nesse modelo, verifica-se que os serviços que compõem a referência de análise explicam 63,6\% da variação da confiança nos fornecedores por parte dos minimercados pesquisados. Especificamente, os valores de $\beta$ indicam que disponibilidade de alternativas de desconto $(\beta=0,597)$, atendimento a pedidos extras ou de urgência $(\beta=0,541)$, treinamento ou apoio ao cliente para o bom uso e manuseio dos produtos $(\beta=527)$, cumprimento dos prazos de entrega $(\beta=0,293)$ e inovação de produtos visando a melhorar o desempenho do cliente $(\beta=0,253)$ impactam positivamente e de forma acentuada na confiança.

Esse resultado demonstra que a confiança está fortemente associada aos serviços ao cliente disponibilizados no canal de marketing e, principalmente, aos serviços que permitem melhorar a performance operacional e econômico-financeira do varejista frente a seus clientes e concorrentes. Considerando-se a confiança como um determinante do comprometimento, quanto maior o poder de explicação da confiança pelo conjunto de serviços, maior a propensão de o comprometimento também ser ex- 
plicado por variáveis de serviços, visto que relacionamentos permeados por confiança são tão valorizados a ponto de as partes comprometerem-se com eles (MORGAN; HUNT, 1994).

A hipótese 6 infere que os serviços ao cliente ofertados influenciam o comprometimento dos varejistas com seus fornecedores. Os resultados encontrados referentes à relação entre os serviços ao cliente e à dimensão comprometimento apresentaram $\mathrm{R}^{2}$ de 0,517 , demonstrando que $51,7 \%$ da variação no comprometimento pode ser explicada pelo conjunto de serviços ao cliente considerados no modelo de análise. Destaca-se o serviço de desenvolvimento de parcerias e acordos de cooperação, por ser o que exerce maior impacto no comprometimento $(\beta=0,637)$. Esse resultado vai ao encontro das proposições de Morgan e Hunt (1994), Vlosky et al. (1998) e Stern et al. (2002), que visualizam as parcerias e alianças estratégicas como fundamentais para o desenvolvimento do comprometimento e, por conseguinte, para o desenvolvimento do marketing de relacionamento nos canais de marketing.

O serviço cumprimento do prazo de entrega do pedido apresenta alto impacto no desenvolvimento do comprometimento $(\beta=0,573)$, da mesma forma que com o atendimento de pedidos extras ou de urgência $(\beta=0,278)$. Essa relação pode estar associada ao fato de que os pequenos varejistas trabalham com baixos estoques, tornando essencial o cumprimento dos prazos de entrega dos produtos e o atendimento a pedidos de urgência, a fim de que possam repor os estoques dentro de prazos adequados.

Por fim, a hipótese 7 contempla que os serviços ao cliente exercem influência no marketing de relacionamento. Os resultados permitem afirmar que o conjunto de serviços ao cliente explica 49,8\% da variância no marketing de relacionamento $\left(R^{2}=0,498\right)$. Entre os serviços ao cliente estatisticamente significativos a $p<0,05$, verificou-se que os que exercem maior impacto são: treinamento ou apoio ao cliente para o bom uso e manuseio do produto fornecido $(\beta=0,554)$, opções de embalagens diferenciadas $(\beta=0,496)$, atendimento a pedidos extras ou de urgência $(\beta=0,469)$, desenvolvimento de parcerias com os clientes $(\beta=0,310)$ e cumprimento do prazo de entrega do pedido ( $\beta=0,259)$. Tais resultados permitiram verificar-se que os serviços ao cliente, quando disponibilizados por parte dos fornecedores, são importantes ferramentas de diferenciação, capazes de ampliar relações de longo prazo com os minimercados. Ainda, os indicadores obtidos ratificam as proposições de Slongo (1996) que, ao referir-se às relações de longo prazo, comenta serem estas caracterizadas por situações nas quais os clientes valorizam a manutenção de fornecedores, apontando os serviços ao cliente como uma oportunidade de diferenciação da oferta central de serviços, facilitando o desenvolvimento de relacionamentos. 


\section{CONCLUSÃO}

Diante dos resultados do estudo, constata-se que entre as seis dimensões de marketing de relacionamento investigadas, tendo-se por referência-base o modelo de Wilson e Vlosky (1997), a dimensão do compromentimento, com uma média aferida pelos respondentes de 4,03, apresenta-se como a de maior importância para os varejistas de pequeno porte. O comprometimento, diferentemente das demais dimensões, apresentou-se relevante nos relacionamentos de troca existentes, demonstrando que os gestores de minimercados percebem valor na relação a ponto de comprometerem-se com o fornecedor.

As demais dimensões do modelo apresentaram médias que oscilaram entre 2,63 e 3,08, sinalizando que investimentos a fim de preservar e fortalecer o relacionamento devem ser mantidos e/ou aprimorados pelos fornecedores. Embora o resultado encontrado na dimensão confiança (média 3,08) seja divergente das proposições de Morgan e Hunt (1994), que posicionam a confiança como principal variável mediadora do comprometimento, observa-se desejo de permanência no relacionamento. Esse fato pode estar relacionado à moderada troca de informações que acontece entre as partes e ao tipo de serviço que ocorre no canal. A existência de muitos fornecedores alternativos nesse canal pode contribuir para uma menor dependência do varejista em relação ao fornecedor, bem como aumentar a possibilidade de troca de fornecedor sem prejuízos para o varejista, caso esta seja sua opção.

No que se refere aos serviços disponibilizados pelos fornecedores, o cumprimento do prazo de entrega do pedido $(4,14)$ surge como o item de maior importância por parte dos varejistas. No outro extremo, a promoção de encontros ou seminários com o propósito de se usufruirem ou melhorarem conhecimentos dos clientes quanto ao bom uso do produto oferecido $(2,27)$ foi considerada o serviço de menor importância para os varejistas. Tendo por referência o conceito de que os fluxos de marketing são os elementos realizados pelo canal de marketing (COUGLAN et al., 2011), a ênfase atribuída em termos de serviço ao cliente por parte dos minimercados está no fluxo do pedido, o que se justifica pela importância aferida ao cumprimento do prazo de entrega dos pedidos por parte de seus fornecedores.

A metodologia utilizada permitiu apontar o grau de explicação dos serviços ao cliente para cada uma das dimensões de marketing de relacionamento, ao mesmo tempo que identificar quais itens de serviços gerados na etapa exploratória têm maior influência em cada variável dependente estudada. Ao serem descritas as relações cau- 
sais entre os serviços ao cliente e as dimensões do marketing de relacionamento, os resultados encontrados no estudo ratificam a importância dos serviços ao cliente nos canais de marketing, enfatizando a sua importância enquanto diferencial competitivo frente à oferta dos concorrentes (COVA, 2008).

Entre as principais descobertas, em uma perspectiva acadêmica e gerencial, ressalta-se a influência dos serviços ao cliente no sentimento de confiança depositado nos fornecedores pelos minimercados pesquisados, a qual explica 63,6\% da variação de confiança nos fornecedores. A construção desse sentimento ocorre, principalmente, por meio da disponibilidade de alternativa de desconto, atendimento de pedidos extras ou de urgência e treinamento ou apoio ao cliente para o bom uso e manuseio dos produtos. Para os fornecedores que atuam nesse modelo de canal, essa informação permite o desenvolvimento de ações que podem promover maior fidelização de seus parceiros, pois aumentam a confiança dos minimercados e, por consequência, ampliam sua capacidade competitiva em relação a canais concorrentes.

Neste estudo verificou-se que a confiança não se apresentou significativa nas relações estabelecidas entre minimercados e seus fornecedores. Entretanto, o comprometimento, diferentemente, apresentou-se relevante nos relacionamentos de troca existentes. Essa constatação diverge das proposições de autores como Morgan e Hunt (1994), que colocam a existência da confiança como variável mediadora do comprometimento. Desse modo, surge uma oportunidade para se investigar, em estudos futuros, como relacionamentos permeados por pouca confiança apresentam alto índice de comprometimento, bem como que variáveis operacionais e/ou ambientais podem impactar nessa relação de mediação.

Os resultados encontrados ratificam a importância dos serviços ao cliente nos canais de marketing e contribuem com o meio acadêmico no sentido de aliar teorias desenvolvidas por pesquisadores a respeito do marketing de relacionamento e de serviços ao cliente à aplicação prática em um segmento altamente competitivo. Também se destaca como contribuição a relação testada e validada no contexto do varejo alimentar de pequeno porte (minimercados) entre os serviços ao cliente e o marketing de relacionamento, permitindo ratificar-se a importância dos serviços ao cliente como fonte de diferenciação nos relacionamentos de micro e pequenas empresas e seus fornecedores.

Considera-se como limitação do estudo a amplitude da população estudada, uma vez que atinge determinado ambiente de canal, tipo de relação de mercado e região geográfica, o que não invalida o estudo, mas abre espaço para replicar o método testado e a validade em outros ambientes e estruturas competitivas. 


\section{REFERÊNCIAS}

ABBADE, E. B.; NORO, G. B. A percepção de clientes universitários quanto ao relacionamento com suas operadoras de telefonia móvel. In: ENCONTRO NACIONAL DA ANPAD, 36., 2012, Rio de Janeiro. Anais... Rio de Janeiro: ANPAD, 2012.

ANDERSON, E.; WEITZ, B. The use of pledges to build and sustain commitment in distribution Channels. Journal of Marketing Research, v. 29, i. 1, p. 18-34, 1992.

BANOMYONG, R.; SUPATN, N. Selecting logistics providers in Thailand: a shippers perspective. European Journal of Marketing, v. 45, i. 3, p. 419-437, 2011.

BARDIN, L. Análise de Conteúdo. Lisboa: Edições 70, 1977.

BERRY, L.; PARASURAMAN, A. Marketing Services. New York: The Free Press, 1991.

BERRY, L. Relationship Marketing. In: BERRY, L. SHOSTACK, G. L.; UPAH, G. D. Emerging Perspectives of Services Marketing. Chicago IL: American Marketing Association, 1983.

BIGGEMANN, S.; BUTTLE, F. Intrinsic value of business-to-business relationships: An empirical taxonomy. Journal of Business Research, v. 65, i. 8, p. 11321138, 2012.

BOWERSOX, D.; DAUGHERTY, P. J. Logistics leadership. Logistics Information Management, Bradford, v. 5, i. 1, p. 12-17, 1992.

CHANG, S. H. et al. Building customer commitment in business-to-business markets. Industrial Marketing Management, v. 41, i. 6, p. 940-950, 2012.

CHRISTOPHER, M. Logística e gerenciamento da cadeia de suprimentos: criando redes que agregam valor. São Paulo: Thomson Learning, 2007.

COSTA R. L.; BARREIROS, L. O outsourcing dos serviços como recurso estratégico de competitividade internacional da economia portuguesa. Revista Gestão e Planejamento, Salvador, v. 14, n. 2, p. 215-231, maio/ago. 2013.

COUGHLAN, A. T. et al. Canais de Marketing. 7. ed. São Paulo: Pearson, 2011. 
COVA, C. J. G. As conexões entre o marketing e a logística na busca do valor ao cliente. Revista Pensamento Contemporâneo em Administração, Rio de Janeiro, v. 2, n. 1, p. 42-53, jan./abr. 2008.

DARONCO, E. Marketing de Relacionamento nas Trocas das Empresas Varejistas de Materiais de Construção de Cruz Alta-RS e Região com seus Maiores Fornecedores. 2001. Dissertação (Mestrado em Administração)-Universidade Federal do Rio Grande do Sul, Porto Alegre, 2001.

DAUGHERTY, P. J.; KASULIS, J.; RICHEY, R. G. The Role of Customer Service in trade Promotion Decision. International Journal of Logistics Management, Ponte Vedra Bezch, v. 13, i. 1, p. 43-56, 2002.

DAY, G. S.; WENSLEY, R. Marketing theory with a strategic orientation. Journal of Marketing, v. 47, i. 4, p. 79-89, 1983.

DEMO, G.; ROZZETT, K. Customer Relationship Management Scale for the Business-to Consumer Market: Exploratory and Confirmatory Validation and Models Comparison. International Business Research, Canadá, p. 29-42, 2013.

DE TONI, D. O relacionamento entre a Vinícola Miolo e seus fornecedores: um estudo comparativo. In: ENCONTRO NACIONAL DA ANPAD, 27., 2003, Atibaia. Anais... Atibaia: ANPAD, 2003.

DWYER, R.; SCHURR, P.; OH, S. Developing Buyer Seller Relationship. Journal of Marketing, v. 51, i. 2, p. 11-27, 1987.

FIGUEIREDO, K. et al. Segmentação logística: um estudo na relação entre fornecedores e varejistas no Brasil. Revista de Administração Contemporânea, v. 11, n. 4, p. 11-31, out./dez. 2007.

FRAZIER, G. L. Organizing and Managing Channels of Distribution. Journal of the Academy of Marketing Science, v. 27, p. 226-240, 1999.

GEIGER, I. et al. The bonding effects of relationship value and switching costs in industrial buyer-seller relationships: An investigation into role differences. Industrial Marketing Management, v. 41, i. 1, p. 82-93, 2012.

GOMES, C. M. et al. Marketing de Relacionamento: um estudo de caso na construção civil. In: ENCONTRO NACIONAL DA ANPAD, 34., 2010, Rio de Janeiro. Anais... Rio de Janeiro: ANPAD, 2010. 
GRÖNROOS, C. Service management and marketing: a customer relationship management approach. New York: John Wiley \& Son, 2000.

GUMMERSSON, E. Relationship Marketing in the New Economy. Journal of Relationship Marketing, v. 1, i. 1, p. 37-57, 2002.

HADJIKHANI, A.; LAPLACA, P. Development of B2B marketing theory. Industrial Marketing Management, v. 42, n. 3, p. 294-305, 2013.

HAIR JÚNIOR, J. F. et al. Análise Multivariada de Dados. Porto Alegre: Bookman, 2005.

HESKETT, J. L.; SASSER, W. E.; SCHLENINGER, L. A. The Service Profit Chain: Low leading companies link profit and growth to loyalty, satisfaction and value. New York: The Free Press, 1997.

INNIS, D. E.; LA LONDE, B. J. Customer service: the key to customer, customer loyalty, and market share. Journal of Business Logistics, n. 15, p. 1-27, 1994.

KLEIN, M. V. Identificação do nível de relacionamento entre a Claro Digital e seus clientes corporativos. 2003. Dissertação (Mestrado em Administração)-Universidade Federal do Rio Grande do Sul, Porto Alegre, 2003.

LA LONDE, B. J.; ZINSZER, P. H. Customer Service: meaning and measurement. A Special Study Report Published by National Council of Physical Distribution Management. Chicago, 1976.

LAMBERT, D. M.; STERLING, J. U. Stabling customer service within the marketing mix. Journal of Business Logistics, v. 8, i. 1, p. 1-30, 1986.

MACNEIL, I. Contracts: adjustment of long-term economic relation under classical, neoclassical and relational contract law. Northwestern University Law Review, i. 72, p. 854-902, 1978.

MACNEIL, I. The New Social Contract, An Inquiry into Modern Contractual Relations. New Haven: Yale University Press, 1980.

MALHOTRA, N. K. Pesquisa de Marketing: uma orientação aplicada. 3. ed. Porto Alegre: Bookman, 2001. 
MORAIS, M. G. Análise do relacionamento na cadeia de suprimentos do setor de eventos de Goiânia, GO. 2010. Dissertação (Mestrado em Administração)-Universidade do Vale do Rio dos Sinos, São Leopoldo, 2010.

MORGAN, R.; HUNT, S. The Commitment of Relationship Marketing. Journal of Marketing, v. 58, i. 3, p. 20-38, 1994.

MORGAN, R. The Evolution of Relationship Marketing Strategy within the Organization. In: SHETH, J.; PARVATIYAR, A. (Ed.). Handbook of Relationship Marketing. Thousand Oaks: Sage Publications, 2000.

MÜSSNICH, R. A. Serviços ao Cliente e Marketing de Relacionamento no Setor Hoteleiro de Porto Alegre. Dissertação (Mestrado em Administração)-Universidade Federal do Rio Grande do Sul, Porto Alegre, 2002.

PATIL, S.; PATIL, Y. S. A review on outsourcing with a special reference to telecom Operations. Procedia - Social and Behavioral Sciences, v. 133, p. 400-416, 2014.

PETERSON, R. A. Relationship Marketing and the Consumer. Journal of Marketing, v. 23 i. 4, p. 278-281, 1995.

ROCHA, A.; LUCE, F. B. Relacionamentos entre compradores e vendedores: origens e perspectivas no marketing de relacionamento. Revista de Administração de Empresas, p. 87-93, jul./set. 2006.

SHANI, D.; CHALASANI, S. Exploiting Niches using Relationship Marketing. Journal of Consumer Marketing, v. 9, i. 6, p. 33-42, 1992.

SHETH, J.; PARVATIYAR, A. The domain and conceptual foundations of relationship marketing. In: SHETH, J.; PARVATIYAR, A. Handbook of Relationship Marketing, Thousand Oaks: Sage Publications, 2000.

SLONGO, L. A.; MÜSSNICH, R. Serviços ao cliente e marketing de relacionamento no setor hoteleiro de Porto Alegre. Revista de Administração Contemporânea, v. 9, n. 1, jan./mar. 149-170, 2005.

SLONGO, L. A. Serviços ao cliente como diferencial competitivo. Análise, Porto Alegre, v. 7, n. 1, p. 219-256, 1996.

STERN, L. W. et al. Canais de Marketing e Distribuição. Porto Alegre: Bookman, 2002. 
VIANA, D. A Proposição de um Modelo sobre Marketing de Relacionamento no Contexto Business-to-Business: avaliação inicial na indústria metal-mecânica do RS. 1999. Dissertação (Mestrado em Administração)-Universidade Federal do Rio Grande do Sul, Porto Alegre, 1999.

VLOSKY, R. et al. Partnerships versus typical relationships between wood products distributor and their manufacturer suppliers. Forest Products Journal, Madison, v. 48, i. 3, p. 27-36, 1998.

WILSON, D. T. An Integrated Model of Buyer-Seller Relationships. Journal of the Academy of Marketing Science, v. 23, i. 4, p. 335-346, 1995.

WILSON, E.; VLOSKY, R. Partnering Relationship Activities: building theory from case study Research. Journal of Business Research, v. 39, p. 59-70, 1997.

ZEITHAML, V.; PARASURAMAN, A.; BERRY, L. L. A Conceptual Model of Service Quality and Its Implications for Future Research. Journal of Marketing, v. 4, i. 4, p. 41-50, 1985.

Como citar este artigo:

ABNT

RIBEIRO, Henrique Cesar Melo; SANTOS, Marianne Corrêa. O impacto dos serviços ao cliente no marketing de relacionamento entre minimercados e seus fornecedores. RACE, Revista de Administração, Contabilidade e Economia, Joaçaba: Ed. Unoesc, v. 15, n. 2, p. 751-778, maio/ago. 2016. Disponível em: <http:// editora.unoesc.edu.br/index.php/race>. Acesso em: dia/mês/ano.

APA

Ribeiro, H. C. M., \& Santos, M. C. O impacto dos serviços ao cliente no marketing de relacionamento entre minimercados e seus fornecedores. RACE, Revista de Administração, Contabilidade e Economia, 15(2), 751-778. Recuperado de http://editora.unoesc.edu.br/index.php/race 
